\title{
Origins and Nature of Vessels in Monocotyledons. 12. Pit Membrane Microstructure Diversity in Tracheary Elements of Astelia $^{1}$
}

\author{
Sherwin Carlquist ${ }^{2,3}$ and Edward L. Schneider ${ }^{2,4}$
}

\begin{abstract}
Xylem of stems and roots of three species of Astelia, a monocot with relatively unspecialized xylem, was examined with scanning electron microscopy (SEM) to better understand structural conditions intermediate between tracheids and vessel elements. Both macerations and hand-sectioned material were studied. Tracheary elements of roots of Asteliaceae can be characterized as tracheids, with some degrees of transition to vessel elements. Pit membrane remnants, which take the form of pores, reticula, or threads, are present commonly in end walls of tracheary elements of roots of Astelia. Stems of Astelia have tracheids with less-conspicuous porosities in the pit membranes of end walls than those of roots. Sectioned materials show that the porose (reticulate) cellulosic layers of the primary wall, which is embedded in a matrix of amorphous material, can be exposed to various degrees by the sectioning process; the cellulosic network faces the lumen, and the amorphous material is the compound middle lamella. Astelia shows stages of transition between vessel elements and tracheids. These character expressions relate to occupancy of moist habitats (Astelia) with steady availability of moisture during the year. There appears to be little difference between a terrestrial species (A. chathamica) and the scandent/epiphytic species $A$. argyrocoma and $A$. menziesiana in terms of tracheary element microstructure, suggesting that habitat is more important than habit as a determinant of tracheary element microstructure and the degree to which lysis of pit membranes occurs. Freehand sectioning of ethanol-fixed materials, as in earlier studies in this series, provides a reliable way of observing pit membrane/ perforation structure when viewed with SEM. Astelia is one of several monocots that demonstrate the difficulty of discriminating between tracheids and vessel elements.
\end{abstract}

Astelia Is now considered an early departing branch of the clade Asparagales (APG III 2009). It is of special interest with respect to microstructure of tracheary elements because, like Orchidaceae (also of Asparagales, but not a sister group to Asteliaceae), Astelia has tracheary elements intermediate between

\footnotetext{
${ }^{1}$ Manuscript accepted 8 December 2009.

2 Santa Barbara Botanic Garden, 1212 Mission Canyon Road, Santa Barbara, California 93105.

${ }^{3}$ Corresponding author (e-mail: s.carlquist@verizon .net).

${ }^{4}$ E-mail: eschneider@sbbg.org.
}

Pacific Science (2010), vol. 64, no. 4:607-618

doi: $10.2984 / 64.4 .607$

(C) 2010 by University of Hawai'i Press

All rights reserved tracheids and vessel elements. Orchidaceae were reported to have vessels in roots only, with scalariform perforation plates in vessels in roots (Cheadle 1942). Our studies of xylem of Orchidaceae (Carlquist and Schneider 2006) confirmed Cheadle's findings, but we were able to take advantage of scanning electron microscopy (SEM). We showed that pit membrane remnants (microfibrillar webs) occur in the perforations of vessels in roots of the majority of the orchids that we studied. The presence of such webs, not visible with light microscopy, suggests that the transition from tracheids to vessels (in which absence of pit membranes in perforations has usually been assumed when using light microscopy) is incomplete. The tracheary elements of stems and inflorescence axes of Orchidaceae are best called tracheids, but they have vari- 
ous degrees of porousness in pit membranes of end walls, suggesting a "pre-vessel" configuration. Cheadle and Kosakai (1971) reported vessels with long scalariform perforation plates in roots of Astelia and Milligania but tracheids in stems of the two genera. Cheadle and Kosakai (1971) did not have the advantage of SEM and therefore could not observe degrees of transition (as represented by pit membrane presence in perforation plates) between vessel elements and tracheids. Astelia proved to be ideal material for showing the microstructure of tracheary element walls in monocots and degrees of intermediacy between tracheids and vessel elements.

Understanding of tracheary elements is complicated, rather than simplified, by examples from monocots such as Asteliaceae and Orchidaceae. The definitions in current use are based in light microscopy, in which end walls of vessels clearly have perforations devoid of pit membranes, whereas end walls of tracheids have pits with pit membranes. In addition, colloidal India ink particles have been used to demonstrate the size of openings in perforations, through which such particles pass, as compared with the supposed nonporousness of pit membranes of tracheids (Cheadle 1942). However, a number of monocots have pit membranes with pores on end walls of tracheary elements of various sizes when seen with SEM (Carlquist and Schneider 2006). Partial pit membranes ("pit membrane remnants") are characteristically present in perforation plates of vessels in a number of dicots (Carlquist 1992). India ink particles may be a test for pore size, but are the size of such particles relevant to physiological differences between tracheids and vessel elements? What is the physiological value of presence of porose pit membranes in end walls of "vessel-like" tracheary elements? In what ecological habitats and regimens are tracheary elements intermediate between vessel elements and tracheids found? If imaging of tracheary elements with SEM is the only accurate way to establish present of pit membranes in end walls, can the definitions established by means of light microscopy be maintained? If they are maintained, what ca- veats must be employed? Astelia is a key group with regard to these questions, because of special features of microstructure of its tracheary elements.

Cheadle (1942) emphasized levels of specialization in monocotyledon xylem, even assigning numerical values to degree of specialization. These trends do occur, but the main determinants of vessel element presence and perforation plate type in monocotyledons are ecological and habital (Carlquist 1975) rather than position within a phylogenetic tree or clade. For example, in onions and allied genera (Alliaceae), there are vessels with simple perforation plates in roots but only tracheids in stems and leaves. This has been interpreted as an adaptation to rapid transport of water by roots, which are short-lived, during brief periods of moisture availability in combination with the conductive safety of tracheids, which restrict spread of air embolisms, within stems and leaves (Carlquist 1975). Orchid roots have longer duration than do the roots of bulbous monocotyledons. That fact may be correlated with the scalariform perforation plates in vessels and, more commonly, tracheids transitional to vessel elements in roots. One could say, in agreement with Cheadle (1942), that these tracheary element expressions are less specialized. One could even imagine that a lower degree of specialization in vessel types in such families as Orchidaceae is due to lack of selection for simple perforation plates because of the mesophytic habitats that these plants occupy. This probably is true in Acoraceae, the family that is a sister group to the remainder of the monocotyledons (Carlquist and Schneider 1997). However, the tracheary elements with scalariform perforation plates in orchids frequently have extensive pit membrane remnants in end walls (Carlquist and Schneider 2006). We see the context for our studies as being primarily of ecology and physiology, and only to a much less extent systematic or phylogenetic in nature. For example, Boryaceae are considered a family of Asparagales that may be close to Asteliaceae (Davis et al. 2004), although resolution is not high currently for branching in phylogenetic trees of Asparagales (APG III 2009). Borya is 
a curious "resurrection plant" that grows on platelike granite outcroppings that are only briefly and seasonally moist. Stems of Borya have tracheids coexisting with vessels, but the vessels have nearly simple perforation plates and the tracheids have circular bordered pits (Carlquist et al. 2008). Such a xylary configuration is closely keyed to ecology and physiology and would not have been predicted on the basis of phylogenetic hypotheses.

Asteliaceae consists of Astelia (sometimes including Collospermum), Milligania, and Neoastelia. Astelia occurs on higher Pacific islands ranging from Hawai' $i$, the Marquesas, and Tahiti to alpine New Guinea, Australia, and Tasmania; it also occurs on Mauritius and Réunion in the Indian Ocean (Wagner et al. 1990). Astelia is especially prominent on New Zealand and is a common component of wet forests in Hawai'i. Astelia habitats are characteristically moist. Astelia can be a moist-forest terrestrial plant or, as in Hawai'i, sometimes an epiphyte with rather elongate stems, usually more common on lower branches of trees and often extending onto the ground in more open areas. Astelia can also be a tufted plant of open "moorland" moist areas, as in New Zealand and Tasmania (Moore and Edgar 1970). In Hawai'i, Astelia ranges from terrestrial plants in bogs or on logs to epiphytes; some plants are scandent on tree trunks and branches and thus are intermediate between terrestrial and epiphyte (Wagner et al. 1990).

\section{MATERIALS AND METHODS}

All studies were based on cultivated material. Plants of Astelia chathamica (Skottsb.) L. B. Moore were obtained from a commercial source (San Marcos Growers, Santa Barbara, California). Specimens of $A$. argyrocoma A. Heller ex Skottsb. (K. Wood 12411) and A. menziesiana Sm. (K. Wood 12402) were kindly provided by David Lorence, of the National Tropical Botanical Garden in Lāwa'i, Kaua'i, and documenting specimens are located there. Portions for study were preserved in $70 \%$ aqueous ethanol. Parts of each collection were sectioned by hand using single-edge razor blades. Sections were then put through three or more changes of distilled water to remove loose starch and mucilaginous materials. Washed sections were placed between glass slides to preserve flatness, air dried on a warming table, and mounted on aluminum stubs. All materials were sputter-coated with gold and examined with an SEM (Hitachi S2600N). Macerations of $A$. chathamica were prepared with Jeffrey's solution, put through changes of distilled water, and stored in 70\% ethanol. Macerated vascular material was spread onto aluminum stubs and air dried on a warming table. Macerated material has the advantage of showing three-dimensional tracheid and vessel element shape as well as revealing the extent and morphology of end walls. Macerated material was used for the preparation in Figures 6,7 , and 13 only. Sectioned material, on the other hand, preserves the pit membranes sensitively (Carlquist and Schneider 2006). Our sampling of Hawaiian species includes all of the taxa recognized in Wagner et al. (1990) except for the extremely rare and endangered A. waialealae Wawra, which is unavailable because of its protected status.

\section{RESULTS}

\section{Astelia argyrocoma (Figures 1-5)}

End walls of root tracheary elements have bars between pits (alternatively, perforations) that are relatively slender (Figures 1-3). The fact that the end walls are differentiated from lateral walls in secondary wall architecture is shown in Figure 3, in which the narrowbarred wall in the foreground (sectioned obliquely) contrasts with the lateral wall pits (background, left) in which pits are narrower and the wall portions between them are wider. The lack of pit membranes (Figure 1, upper) in some pits may be an artifact of sectioning. The pit membranes that are intact (Figure 1, lower) have pores, and the degree of pore exposure may be due to depth of sectioning: the amorphous wall portions are intact in most areas of those pit membranes. The cellulosic network present in some endwall pit membranes is illustrated in Figure 2 (areas of absence of the network, as in center, 


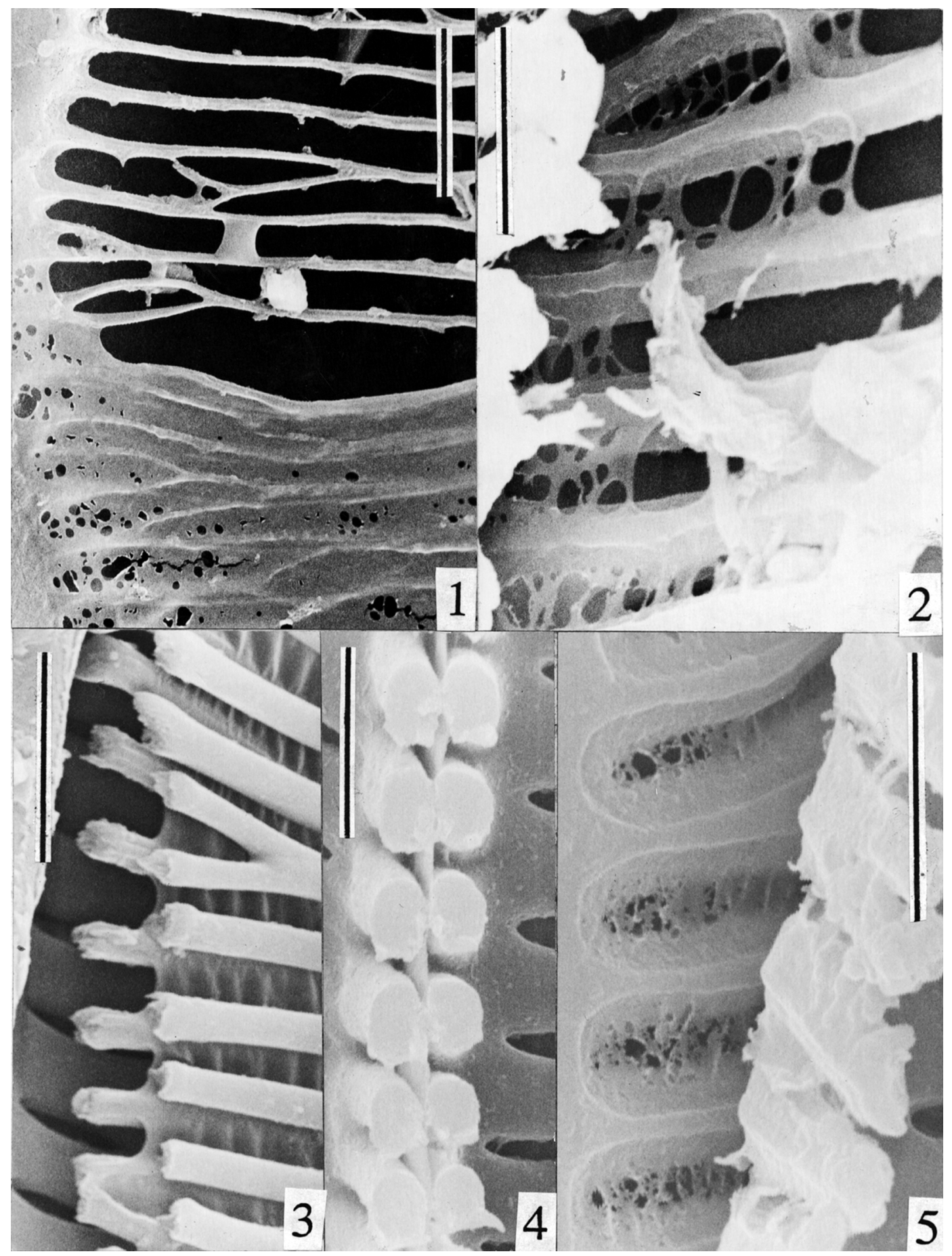

Figures 1-5. SEM photographs of tracheary elements from roots (1-3) and stems (4-5) of Astelia argyrocoma. (1) Perforation plate portion; upper portion is devoid of wall material, but lower portion has porose membranes. (2) Perforation plate portion seen from outside of cell; a reticulate cellulosic layer is exposed. (3) Sectional view of portion of a perforation plate; pit membrane portions show corrugations (an artifact) but no porosities. (4) Lateral wall portion in face view; pit membranes are intact and show a nonporous texture. (5) Portion of a perforation plate in which the two facing cells have been ripped apart by the sectioning process; both show porous or reticulate microstructure. Scales: 1 , $10 \mu \mathrm{m} ; 2,5 \mu \mathrm{m} ; 3,10 \mu \mathrm{m} ; 4,5 \mu \mathrm{m} ; 5,5 \mu \mathrm{m}$. 
right, are probably due to sectioning or tearing away of the cellulosic network). The bars of the end wall do bear borders (Figure 3). Such borders are clearly present on lateral wall pits (Figure 4) of stem tracheids. The stem tracheary element end wall in Figure 5 clearly shows borders (left). The two adjacent cells of the end wall (Figure 5) have been ripped apart by the sectioning, revealing porose pit membranes. Thus, there is apparently little difference between roots and stems in $A$. argyrocoma with respect to wall presence and occurrence of porosities: end walls with either porous or nonporous pit membranes may be found in tracheary element end walls of both roots and stems.

\section{Astelia chathamica (Figures 6-14)}

The roots of $A$. chathamica sometimes have tracheary element end walls that seem to be clearly demarcated as perforation plates (Figures 6,7), most with more than 20 bars (Figure 6). The bars of the perforation plates are slender and separated by rather wide perforations, in contrast to the lateral wall pitting (Figure 7, upper right; Figure 8, left). Pit membranes are well retained in macerated material. Some pit membrane remnants may be seen in macerated material (Figure 9). Sectioned material retains pit membranes more reliably (Figures 8, 10). An oblique section of an end wall (Figure 8) shows pit membrane remnants as linear strands, oriented axially. An end wall from a macerated preparation (Figure 9) shows a reticulate pattern of pit membrane remnants. The oblique section illustrated in Figure 10 shows a portion of a perforation plate; on the front side, the pit membrane remnants are reticulate; on the back side, the pit membranes are intact and nonporose.

Some tracheary elements of roots (Figures 11,12 ) have end walls in which the bars are relatively wide and contain pit membranes to various degrees. The shape and size of these end wall pits are like those of lateral wall pits (Figure 11, lateral wall shown obliquely adjacent to the end wall, at right). In the end wall portion shown in Figure 12, a variety of pit membrane remnants is evident. The lack of tearing in the pit membrane remnants, espe- cially in the delicate threadlike portions, suggests that artifact formation may be minimal. Some patches of intact pit membrane portions are present, but a reticulum of threads is present in most of the pits shown. The presence of solid pit membrane portions may indicate that less of the wall has been shaved away in those places, whereas threads and reticulate appearances may represent areas where the amorphous wall portions have been scraped away by the sectioning.

In the stem of $A$. chathamica, we observed a few tracheary element end walls in which small circular pores were present (Figures 13, 14). Most tracheary elements, however, show only nonporose intact pit membranes.

\section{Astelia menziesiana (Figures 15-22)}

End walls of root tracheary elements have numerous bars, often narrow (Figures 15, 16) but sometimes wider (Figures 17, 18). Borders are clearly present on the wider bars (Figures 17, 18). The perforation plate of Figure 15 appears to contain few pit membrane remnants, but that absence might be explainable by sectioning away of pit membrane portions, because the view of the perforation plate is from the outside of the cell. A view of an end wall from inside a cell (Figure 16) appears to represent the intact condition of the pit membranes, with no removal of wall material by sectioning evident. In the end wall of Figure 16 numerous pores of various sizes are evident. These pores are presumably intercontinuous between one tracheary element and the next tracheary element in a vertical series. Reticulate and porose pit membrane portions of pit membranes are illustrated in Figures 17 and 18. Clearly, some pit membrane portions have been removed in Figure 17 (note the absence of bar portions, correlative with absence of pit membrane, in the upper half of Figure 17).

The end walls of tracheids of stems of $A$. menziesiana (Figures 19-22) show little differentiation from the lateral walls: the bars are about the same width as the pit cavities. The bars are clearly bordered (Figures 20-22). From the outside of the cells (Figures 1921 ), one sees various degrees of presence of a reticulate cellulosic network. The differences 


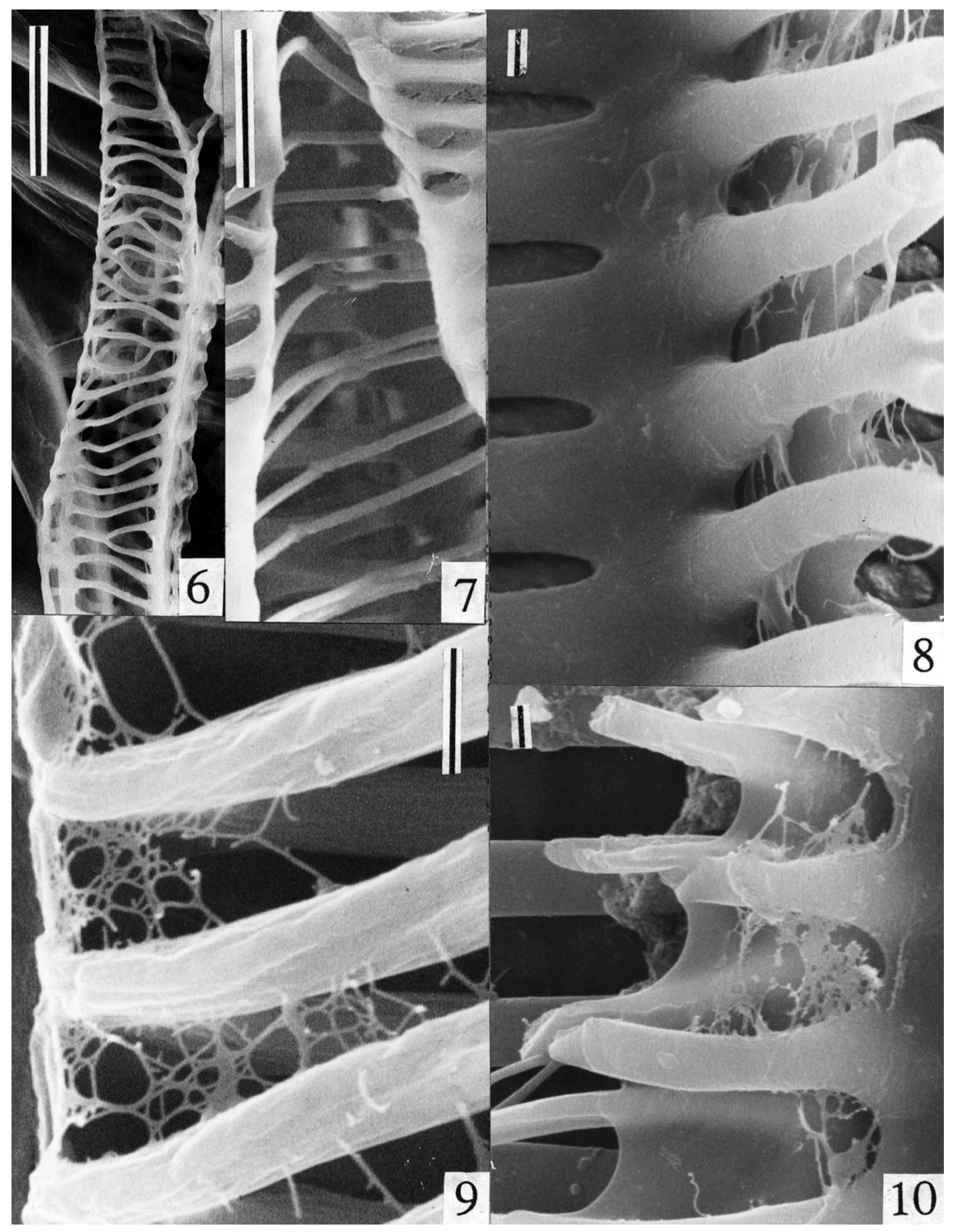

Figures 6-10. SEM photographs of tracheary elements from roots of Astelia chathamica. (6) About two-thirds of a perforation plate, showing narrow bars. (7) Tip of a perforation plate; lateral wall pitting of adjacent vessel element (above, right) shows presence of pit membranes. (8) Threadlike pit membrane remnants (right) contrast with nonporose pit membranes of lateral wall pits (left). (9) Reticulate pit membrane remnants on end wall. (10) Pit membrane remnants in front of apparent nonporose pit membranes in an end wall. Scales: $6,20 \mu \mathrm{m} ; 7,10 \mu \mathrm{m} ; 8,10,1 \mu \mathrm{m} ; 9,2$ $\mu \mathrm{m}$. 


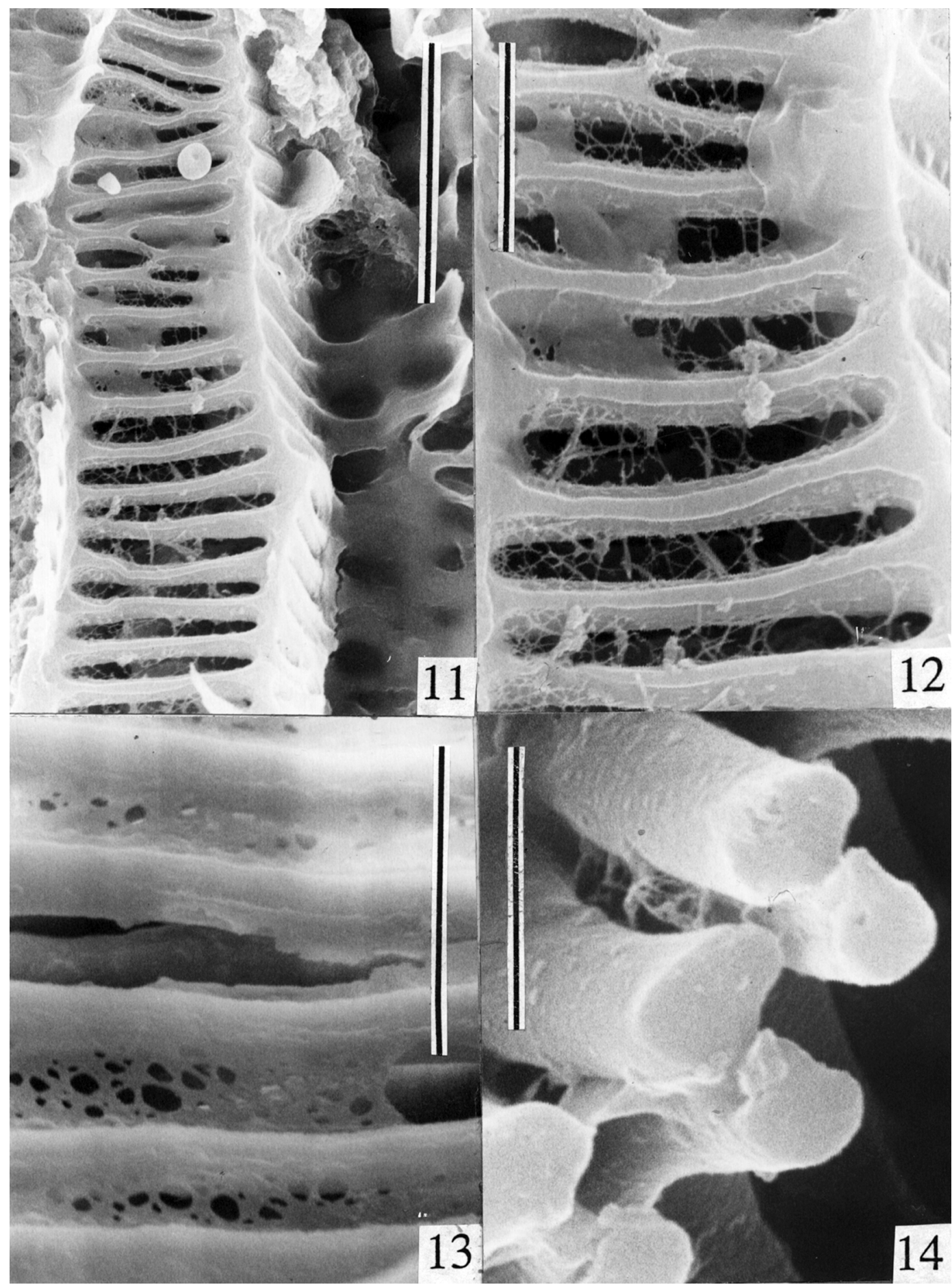

Figures 11-14. SEM photographs of tracheary elements from roots (11-12) and stems (13-14) of Astelia chathamica. (11-12) Portions of end wall from sectioned material. (11) About half of the length of an end wall; pit membrane reticulum is more porose in the central portion of the end wall. (12) Detail to show meshworklike and nonporose portions of pit membrane remnants. (13) Portion of end wall from maceration. Small circular pores are present in the pit membrane. (14) Portions of tracheid end wall sectioned obliquely; pit membranes are distorted by not being flat but have small porosities. Scales: $11,10 \mu \mathrm{m} ; 12,13,5 \mu \mathrm{m} ; 14,2.5 \mu \mathrm{m}$. 


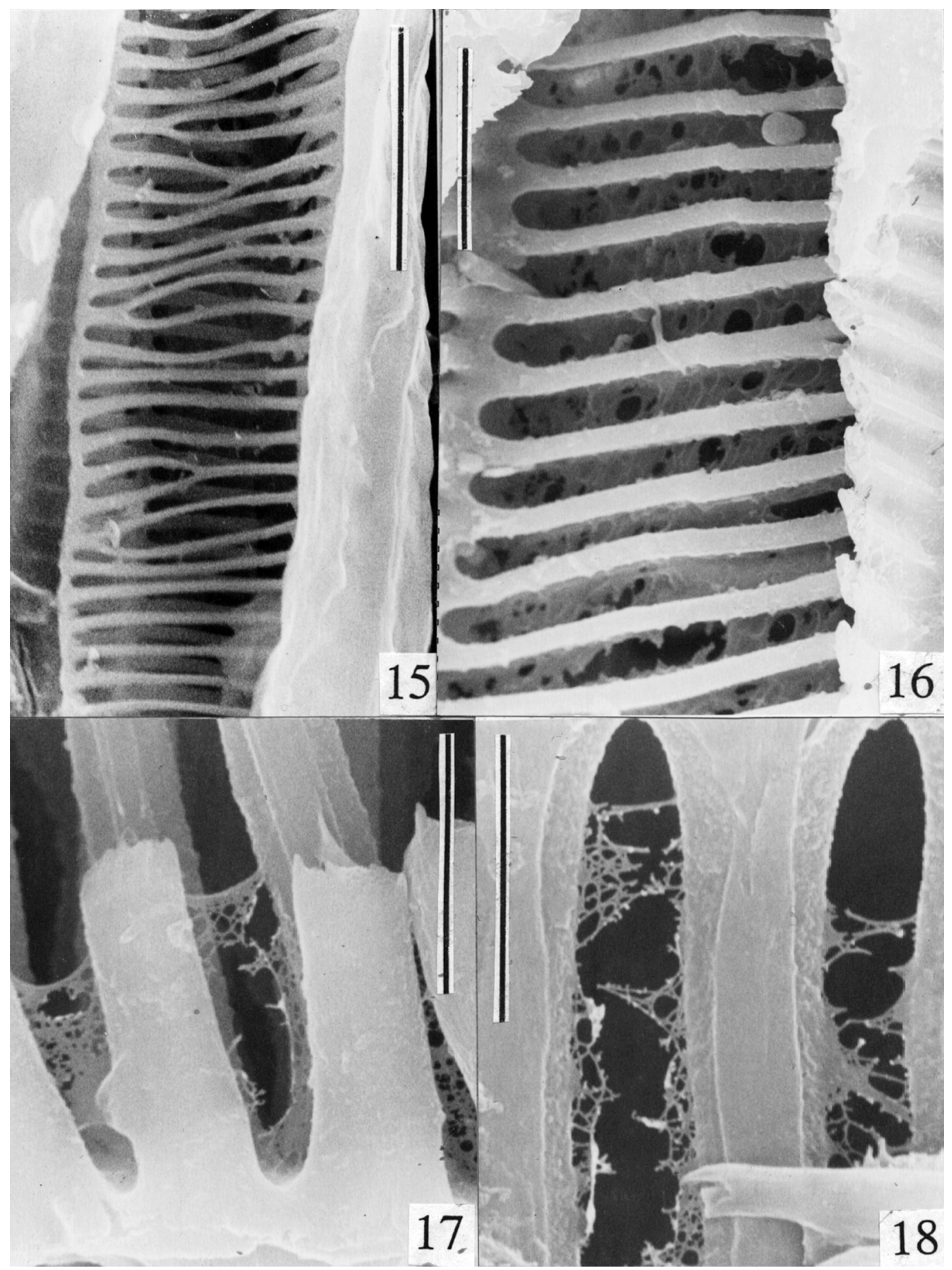

Figures 15-18. Portions of end walls in tracheary elements of roots of Astelia menziesiana (K. Wood 12402). (15) Central portion of an end wall, showing a few fragments of primary walls in the perforations. (16) Portion of a perforation plate: pit membrane remnants are extensive. (17) Lateral ends of pits (perforations) on end wall, showing a porose network in lateral ends of pits; tears in membranes are artifacts. (18) Pit membrane remnants in two pits of end wall; some tears (artifacts) are present. Scales: 15, $20 \mu \mathrm{m} ; 16,10 \mu \mathrm{m} ; 17,5 \mu \mathrm{m} ; 18,5 \mu \mathrm{m}$. 
in degree of presence of porose versus nonporose pit membranes in Figure 19 can be explained by the sectioning process. The central portion of the end wall in Figure 19 is shaved away: the amorphous matrix has been retained at the lateral ends of the pits. The fact that Figure 19 represents a view of the outside of a cell and that pit membranes have been scraped away in the central portions of the pits (Figure 19) is interpreted by us as indicating that the cellulosic network (shown in Figures 20,21) faces the lumen of each cell, whereas the amorphous materials (compound middle lamella) lie between the two cells. A sectional view of the end wall of a tracheid (Figure 22) shows vertical folding in the pit membrane. This is an artifact occasionally found as a result of delicacy of the wall combined with heating by the electron beam. The pit membrane in Figure 22 does show, however, pores that interconnect the two cells. The sectional view rules out that pores are the result of any shaving-away action of the sectioning process.

\section{DISCUSSION}

The three species of Astelia show similar patterns in tracheary element microstructure. Both roots and stems show some differentiation of end walls (bars narrower, pits wider) from lateral walls (secondary wall between the pits wider, pits narrower). Both end walls and lateral walls are scalariform in secondary wall architecture. Porose pit membranes as well as, less commonly, nonporose pit membranes are commonly found in end walls of tracheary elements of both stems and roots. In tracheids of both stems and roots, the pores vary in size and extensiveness, but (discounting artifacts) the size and abundance of pores are not so pronounced that one can say that vessel elements rather than tracheids are present. In fact, Astelia is a wonderful genus for showing the tracheary elements intermediate between tracheids and vessel elements. We have taken into account that some end wall pit membranes may show porousness of end walls due to sectioning away of amorphous wall material. Differential removal of nonporous wall material by sectioning does not account, however, for instances in which one can see porose pit membranes in end walls from the inside of a tracheary element (e.g., Figures 1, 8, 14, 22). These four photographs prove that porose walls not likely to represent any artifacts may be found. The cellulosic networks basic to the porose appearance face the lumen, whereas amorphous wall portions represent the so-called compound middle lamella (primary walls of a pair of cells in contact, plus the intervening intercellular cementing substance).

Cheadle and Kosakai (1971) reported vessel elements with long scalariform perforation plates in roots, but only tracheids in stems, of one species of Astelia and three of Milligania. However, because Cheadle and Kosakai (1971) used light microscopy, they were unable to see pit membrane remnants in perforation plates, and thus their terminology is not usable today. On the basis of our sampling, Astelia has tracheids transitional to vessel elements in roots and tracheids in stems.

The xylem of Astelia is entirely congruent with the character states reported in Orchidaceae (Carlquist and Schneider 2006). In turn, the apparently most primitive xylem in monocotyledons, that of Acorus, differs only in having large porosities in root tracheary elements rather than clear perforations (Carlquist and Schneider 1997). Arguably, one can designate the root tracheary elements of Acorus as tracheids transitional to vessel elements. The wide phylogenetic distances between Acoraceae, Asteliaceae, and Orchidaceae are clear, and these examples are presented as instances of structural similarities that are not indicative of relationship. Vessels in roots of Astelia and Orchidaceae are really transitional between tracheids and vessel elements by having at least some plates in which both pit membrane remnants and the spaces between the remnant strands are about equal in area. The traditional definitions of tracheids and vessels are based upon light microscopy, which cannot reveal the presence of pit membrane remnants (or even intact pit membranes) because pit membranes often stain too lightly). The traditional definitions of vessel elements depend on differences between perforation plates and lateral walls in 


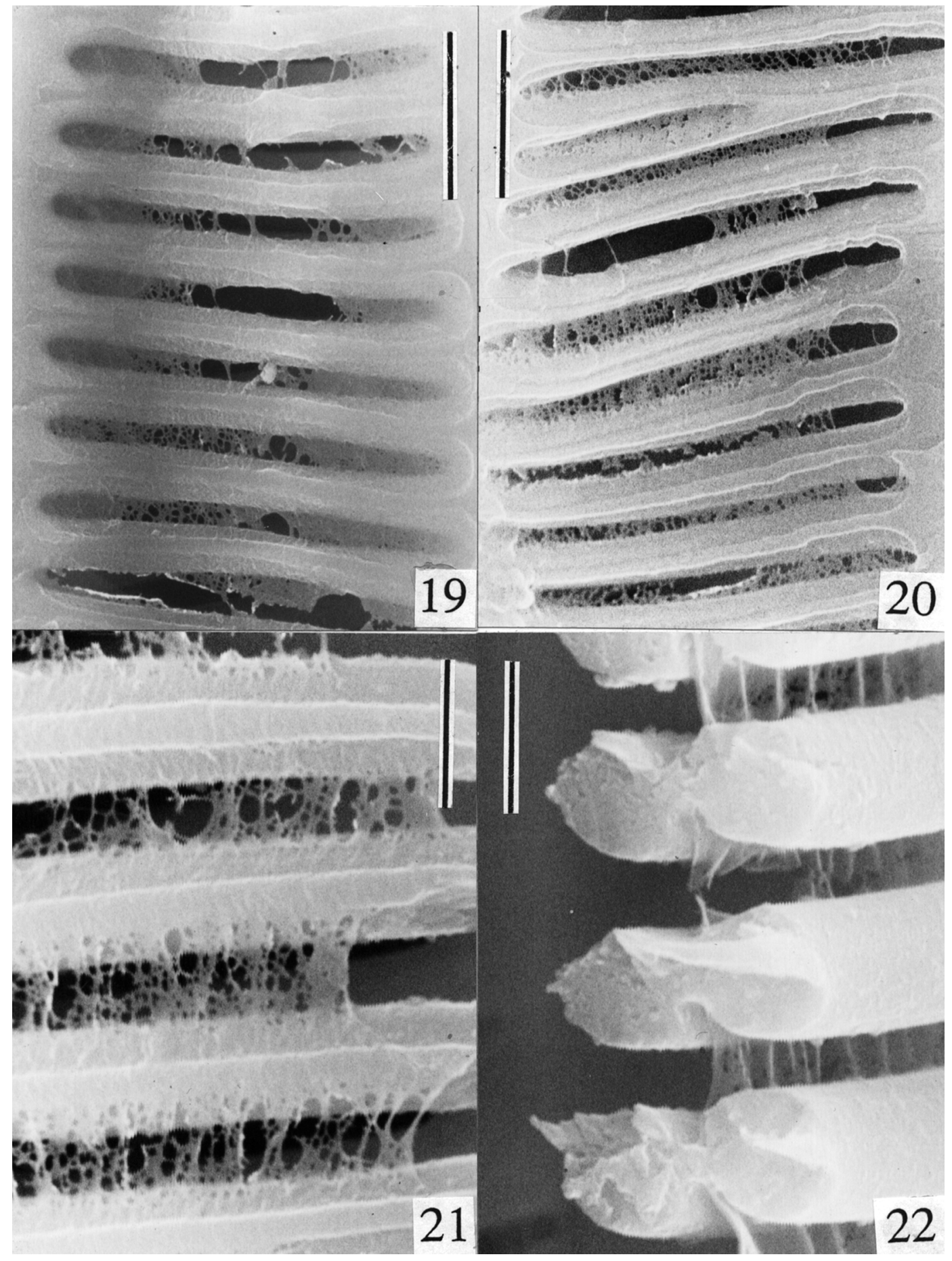

Figures 19-22. Portions of end walls of tracheary elements in stems of Astelia menziesiana (K. Wood 12402). (19) Central portion of end wall; less end-wall material is present in central portions of pits due to sectioning, but portions of a cellulose network are revealed. (20) Central portion of an end wall, showing a rather uniform distribution of cellulosic remnants. (21) Portions of three pits, showing that the cellulosic network extends over the pit borders. (22) Sectional view of the end wall between two tracheary elements, showing borders on pits and, in the striate pit membrane (the corrugations are artifacts), some small porosities. Scales: 19, 20, $5 \mu \mathrm{m} ; 21,22,2 \mu \mathrm{m}$. 
secondary wall architecture, not merely on pit membrane presence. The character state contrast ("vessels absent" versus "vessels present") in data matrices in cladistic work is not realistic. There is no designation for transitional tracheary elements in these constructs, and assignment to such a category would depend largely on which taxa with such elements had been studied with SEM and which had been studied only with light microscopy.

Ecological considerations have played a role in interpretation of monocotyledon $\mathrm{xy}$ lem (Carlquist 1975). However, the roots of Astelia show much less specialization for high conductive efficiency (which would be represented by simple perforation plates) than does the xylem of most monocots. The Astelia species studied have roots that are relatively long-lived and somewhat succulent, as compared with the roots of Allium, Narcissus, and others, which are relatively slender and may function for only a few weeks. Monocotyledons that have roots with relatively greater longevity tend to show scalariform perforation plates (e.g., Orchidaceae [Carlquist and Schneider 2006]). Monocotyledons that have a bulbous habit or that grow in habitats with marked seasonality in moisture availability (Agave) tend to have simple perforation plates in roots (Carlquist 1975). The lack of difference between root tracheary elements and stem tracheary elements suggests that root xylem of Astelia, like that of the stems, is mesomorphic. The species of Astelia studied here, as well as others, do not characteristically occupy habitats subject to marked fluctuation in moisture availability (Moore and Edgar 1970, Wagner et al. 1990). The presence of pit membranes in end walls of tracheary elements of monocots such as Astelia may represent a history of extended occupancy of mesic situations.

The relatively moderate differentiation between end walls and lateral walls in tracheary elements of both stems and roots, as well as retention of pit membranes in end walls of tracheary elements, suggests that one should term the xylem cells of Astelia tracheids rather than vessel elements. The absence of pit membrane remnants in the end walls of A. chathamica root tracheary elements (Fig- ures 6,7$)$ may result from removal of primary wall material by the macerating process (note, however, the presence of pit membranes in lateral wall pits in that preparation [Figure 7]). Earlier (Carlquist and Schneider 2006), we offered the opinion that tracheary elements with extensive pit membrane remnants are essentially more like tracheids in functional aspects. The tracheary elements of $A s-$ telia seem to confirm this idea. Porosities in end walls of the tracheary elements may offer a modest increase in water conduction ability as compared with lack of porosities. However, the pores are probably too small to permit transfer of air bubbles from one tracheary element to the next in a vertical series, a characteristic of tracheids.

Currently, definitions of tracheids and vessel elements based on light microscopy are workable for situations where the perforation plates of vessels are well marked and contrast well with lateral walls with respect to secondary wall architecture (perforations later than pits, separated from each other by relatively narrow bars of secondary wall material). The perforation plates of vessel elements, where visible, are assumed to lack pit membranes as currently defined, whereas tracheids have pit membranes in end wall pitting. Astelia tracheary elements cannot be fitted into such a binary system of definitions, such as is practiced by those interested in cladistic applications (vessels present versus vessels absent). We recommend that such tracheary elements be considered and labeled intermediate between tracheids and vessels. Alternatively, one can define such tracheary elements as tracheids, with some vessel-like tendencies (in which case, those tendencies should be explicitly mentioned). This would highlight the ecological and evolutionary significance of such tracheary elements, concepts more important, we believe, than the convenience of fitting cells into definitions that have been superseded by modern knowledge.

\section{ACKNOWLEDGMENTS}

The material of $A$. argyrocoma and $A$. menziesiana (collected by Kenneth Wood) was provided through the kind offices of David 
H. Lorence of the National Tropical Botanical Garden.

\section{Literature Cited}

APG III. 2009. An update of the Angiosperm Phylogeny Group classification for the orders and families of flowering plants. Bot. J. Linn. Soc. 161:105-121.

Carlquist, S. 1975. Ecological strategies of xylem evolution. University of California Press, Berkeley.

- 1992. Pit membrane remnants in perforation plates of primitive dicotyledons and their significance. Am. J. Bot. 79:660-672.

Carlquist, S., and E. L. Schneider. 1997. Origins and nature of vessels in monocotyledons. 1. Acorus. Int. J. Plant Sci. 158:5156.

. 2006. Origins and nature of vessels in monocotyledons. 8. Orchidaceae. Am. J. Bot. 93:963-971.

Carlquist, S., E. L. Schneider, and K. Kenneally. 2008. Origins and nature of vessels in monocotyledons. 10. Boryaceae: Xeromorphic xylem structure in a resurrection plant. J. R. Soc. West. Aust. 91:13-20.
Cheadle, V. I. 1942. The occurrence and types of vessels in the various organs of the plant in the Monocotyledoneae. Am. J. Bot. 19:441-450.

Cheadle, V. I., and H. Kosakai. 1971. Vessels in Liliaceae. Phytomorphology 21:320333.

Davis, J. V., D. W. Stevenson, G. Petersen, O. Seberg, L. M. Campbell, J. V. Freudenstein, D. H. Goldman, C. R. Hardy, F. A. Michelangeli, M. P. Simmons, C. D. Specht, F. Vergara-Silva, and M. Gandolfo. 2004. A phylogeny of the monocots, as inferred from $r b c L$ and atpa sequence variation, and a comparison of methods for calculating jackknife and bootstrap values. Syst. Bot. 29:467-510.

Moore, L. B., and E. Edgar. 1970. The flora of New Zealand: Monocotyledons other than grasses. Department of Scientific and Industrial Research, Wellington, New Zealand.

Wagner, W. L., D. R. Herbst, and S. H. Sohmer. 1990. Manual of the flowering plants of Hawai'i. Vol. 2. University of Hawai'i Press and Bishop Museum Press, Honolulu. 